\title{
A intertextualidade como elemento de base construtiva em $O$ ano da morte de Ricardo Reis, de José Saramago
}

\author{
Susanna Ramos Ventura*
}

\begin{abstract}
Resumo: O presente ensaio analisa o papel da intertextualidade como elemento de base construtiva do romance $O$ ano da morte de Ricardo Reis, do escritor português José Saramago. Para tanto, busca apoiar-se na teorização clássica sobre intertextualidade - proposta por Julia Kristeva e aprofundada por Laurent Jenny - bem como em reinterpretações do conceito - como a efetuada por Sandra Nitrini - para iluminar procedimentos adotados por José Saramago nesta obra, uma das mais significativas da produção do escritor. O resultado artístico obtido parece instar o leitor a uma postura ativa, de busca por sentidos que se revelam a partir da interpretação e decifração de camadas de intertexto.
\end{abstract}

Palavras-chave: intertextualidade; romance português contemporâneo; leitor.

\begin{abstract}
This essay analyzes the role of intertextuality as a constructive element of the novel The year of the death of Ricardo Reis, by the Portuguese writer José Saramago. In order to achieve this proposal, this article relies on the classical theory proposed by Julia Kristeva and further developed by Laurent Jenny, as well as reinterpretations of the concepts involved, such as Sandra Nitrini's approach, in order to enlighten procedures adopted by José Saramago in The year of the death of Ricardo Reis, one of his most significant works. The artistic result obtained seems to urge the reader to assume an active attitude in search of meanings that are revealed from the interpretation and understanding of intertext layers.
\end{abstract}

Keywords: intertextuality; Portuguese contemporary novel; reader

A análise do papel da intertextualidade no romance $O$ ano da morte de Ricardo Reis (1984), do escritor português José Saramago, parece-nos ter vital importância para a completa fruição da obra. Desta maneira, gostaríamos de examinar a questão da intertextualidade considerando-a como elemento de base construtiva da obra em questão.

A teoria da intertextualidade proposta por Julia Kristeva aponta para a realidade do texto como resultado de relações com outros textos, discursos e ideologias. Cada texto escrito estaria relacionado a um outro texto ou a um conjunto de textos. Segundo Sandra Nitrini, o texto literário seria "uma escritura-réplica de um outro (outros textos). Pelo seu modo de

\footnotetext{
* Susanna Ramos Ventura é doutora em Letras pela Universidade de São Paulo (2006), com tese em literatura comparada sobre os romances de Ana Maria Machado (Brasil), José Saramago (Portugal) e Mia Couto (Moçambique). Escreve material didático para Ensino Médio e Superior (Ensino de Letras à Distância) e ministra aulas de literaturas de língua portuguesa.
} 
escrever, lendo o corpus literário anterior ou sincrônico, o autor vive na história e a sociedade se escreve no texto" (NITRINI, 1997, p.162).

Laurent Jenny (1979), em seu artigo "A estratégia da forma", diz sobre a intertextualidade:

O que caracteriza a intertextualidade é introduzir a um novo modo de leitura que faz estalar a linearidade do texto. Cada referência intertextual é o lugar duma alternativa: ou prosseguir a leitura, vendo apenas no texto um fragmento como qualquer outro, que faz parte integrante da sintagmática do texto - ou então voltar ao texto-origem, procedendo a uma espécie de anamnese intelectual em que a referência intertextual aparece como um elemento paradigmático "deslocado" e originário duma sintagmática esquecida. $\mathrm{Na}$ realidade, a alternativa apenas se apresenta aos olhos do analista. É em simultâneo que estes dois processos operam na leitura - e na palavra - intertextual, semeando o texto de bifurcações que lhe abram aos poucos, o espaço semântico.

Sejam quais forem os textos assimilados, o estatuto do discurso intertextual é assim comparável ao duma super-palavra, na medida em que os constituintes deste discurso já não são palavras, mas sim coisas já ditas, já organizadas, fragmentos textuais. A intertextualidade fala uma língua cujo vocabulário é a soma dos textos existentes. Opera-se, portanto, uma espécie de separação ao nível da palavra, uma promoção a discurso com um poder infinitamente superior ao do discurso monológico corrente. (1979, p. 21 e 22)

A construção de $O$ ano da morte de Ricardo Reis, desde sua abertura, apresenta uso constante de intertextualidade, em especial com textos da literatura portuguesa.Tomemos como exemplo a frase de abertura do romance: "Aqui o mar acaba e a terra principia" (SARAMAGO,1984, p.11). Esta é uma paráfrase de Camões que, em Os Lusíadas, Canto III, estância 20 escreveu o verso: "Aqui onde a terra se acaba e o mar começa". Passemos, em seguida, à última frase do romance, outra retomada do mesmo verso de Camões; “Aqui onde o mar se acabou e a terra espera" (SARAMAGO, 1984, p. 415).

A intertextualidade com a obra de Camões é visível e introduz, como na citação de Jenny, a um modo de leitura que rompe com a linearidade do texto. Nestes dois momentos do romance, o leitor se vê na encruzilhada apontada pelo teórico: ou prossegue a leitura sem identificar o texto de origem, ou volta a ele em busca de elementos que o ajudem a compreender o que o autor do romance deseja com este procedimento.

No caso tomado como exemplo, vemos o verso camoniano que, celebrando a época das conquistas marítimas, anuncia o término do território português, ao mesmo tempo em que o mar começa, imenso território aquático percorrido pelos portugueses em busca de riquezas e de outras terras para colonização.

Quando José Saramago retoma o verso, na frase inicial do romance, transforma seu sentido. Desta vez ele nos estabelece que a terra da qual vai falar se inicia quando o maracaba. Tânia Franco Carvalhal nos fala sobre esta primeira frase do romance de Saramago:

A frase introdutória é um verso camoniano, cuja entonação épica e ordem de termos nos remetem a um sentido inaugural e esclarecedor: o que se narra é o ato de chegar. Ali se chega por mar como em uma descoberta, e por isso quando este finda surge o que começa - a terra. 
Pode-se falar aqui de (re)descoberta, pois trata-se de um retorno à terra conhecida. (BERRINI, 1999, p.115)

Portanto, se estabelece de início, com o leitor que conhece o verso de Camões, uma relação entre Os Lusíadas, onde se narra a epopéia dos portugueses em sua conquista ultramarina, e $O$ ano da morte de Ricardo Reis onde, pelo que se depreende da leitura desta primeira frase, tratar-se-á do "retorno à terra conhecida", Portugal, portanto, de uma viagem de regresso.

A última frase do romance informa que a narrativa que se encerra convergiu para este ponto: "onde o mar se acabou e a terra espera". Portanto, ao final da narrativa, a terra, Portugal, continua à espera de algo. O romance tematiza o ano de 1936, a ditadura de Salazar e o sufocamento do levante dos marinheiros que pretendia devolver a democracia ao país. Portanto, a terra espera a liberdade.

Voltando ao teórico Laurent Jenny, podemos ver, no exemplo acima, o discurso intertextual onde os trechos apontados constituem a chamada "super-palavra", pois, se Saramago poderia ter expressado as mesmas idéias por outras palavras, escolheu revisitar o verso camoniano e assim, as duas frases/versos colocadas em relevo se encaixam no que Jenny definiu como "coisas já ditas, já organizadas", no caso, o verso camoniano que já traz no seu bojo uma série de significados próprios, que são apropriados e subvertidos pelos novos enunciados na criação de Saramago, abrindo o espaço semântico.

Outro exemplo está no barco que chega nas primeiras linhas do romance: ele é escuro e sobe o fluxo soturno do rio, o que evoca as Odes 317 e 322 de Ricardo Reis (PESSOA, 1983), em que o barco escuro que sobe o rio soturno é o barco da morte, onde o poeta terá seu encontro fatal. Que a mencionada viagem de regresso à terra conhecida seja feita no barco da morte, é uma descoberta que se faz por meio da intertextualidade e que abre o sentido do discurso, dando pistas ao leitor sobre a história que lhe será narrada a partir de tais conjunções de sentido. A multiplicidade de intertextos no que diz respeito especificamente ao rio daria por si só motivo para todo um ensaio. No entanto, para o âmbito deste trabalho, teceremos apenas breves considerações a esse respeito.

No início do romance, a descrição da rota do navio Highland Brigade revisita o poema XX de "O Guardador de Rebanhos" de Alberto Caeiro: "ainda tocará em Vigo e Boulognesur-Mer, enfim entrará o Tamisa, como agora vai entrando o Tejo, qual dos rios o maior, qual a aldeia" (SARAMAGO, 1984, p.11). O mesmo poema será novamente trazido à baila quando Ricardo Reis passeia pelo cais e revê os contratorpedeiros com nomes de rios: "havia o Tejo, 
que no Tejo está, e o Vouga, e o Dão, que é este mais perto [...] aqui estão os rios que correm pela minha aldeia" (SARAMAGO, 1984, p.115).

A Ode 315 de Ricardo Reis exorta a pastora Lídia a sentar-se ao lado do poeta à beira do rio (PESSOA, 1983). Esta paisagem típica da poesia horaciana, da "pastora" e do poeta sentados em lugar tranqüilo e bucólico, junto a uma natureza idealizada de campos gramados e com flores, com um rio de águas calmas e límpidas, será confrontada, no texto de Saramago, coma paisagem real da cidade de Lisboa, e de um rio que em grande parte da ação é descrito como sujo, turvo, enlameado e turbulento.

Ricardo Reis, no entanto, preso à imagem idealizada de suas Odes, define-se para Marcenda como: "Um homem sossegado, alguém que se sentou na margem do rio a ver passar o que o rio leva, talvez à espera de se ver passar a si próprio na corrente" (SARAMAGO,1984, p.291). Como um todo, podemos afirmar que os fragmentos intertextuais que, no romance, remetem à obra dos heterônimos pessoanos, se encarregam de criar para Ricardo Reis e Álvaro de Campos um novo sentido, expandindo o seu significado primitivo.

Uma vez mais recorremos a Laurent Jenny quando nos diz que o vanguardismo intertextual é sábio, pois está "ao mesmo tempo consciente do objetivo sobre o qual trabalha, e das recordações culturais que o dominam”. Ressalta ainda que o papel deste vanguardismo é o da re-enunciação de discursos “cujo peso se tornou tirânico" (JENNY, 1979, p.44).

As afirmativas acima espelham os procedimentos utilizados na urdidura textual de $O$ ano da morte de Ricardo Reis, onde são retomados Camões, Ricardo Reis, Álvaro de Campos, Alberto Caeiro, Fernando Pessoa, Eça de Queirós entre outros escritores portugueses de várias épocas, bem como outras fontes textuais como, por exemplo, a Bíblia.

Assim, pela composição em que se entrelaçam discursos prévios e novos enunciados, os sentidos dessa nova trama textual são dinamizados, multiplicados, ganhando em sentido e apontandopara direções diversas daquelas dos discursos originais.

Ricardo Reis busca na memória fragmentos de seus versos e murmura: "Não a ti, Cristo, odeio ou menosprezo", verso da Ode 343 (PESSOA, 1983), e o narrador nos diz:

... há um momento em que duvida se terão mais sentido as odes completas... do que este juntar avulso de pedaços ainda coerentes porém já corroídos pela ausência do que estava antes ou vem depois, e contraditoriamente afirmando, na sua própria mutilação, um outro sentido fechado, definitivo como é o que parecem ter as epígrafes postas à entrada dos livros. (SARAMAGO, 1984, p. 66)

O autor manobra habilmente fragmentos de discurso histórica ou literariamente registrado, o discurso do narrador e das personagens, para promover sentidos diversos, vão se 
emaranhando à narrativa ficcional, fazendo com que o leitor deva estar atento o tempo todo às mudanças nos discursos conhecidos e sua transformação de sentido, que constrói um novo discurso.

No que diz respeito, por exemplo, à utilização do conteúdo de jornais da época para a composição da narrativa, José Saramago lança mão deste recurso de maneira muito abundante e eficiente neste romance, sendo que o leitor percebe claramente o que Laurent Jenny enuncia na citação abaixo:

Abre-se então o campo duma palavra nova, nascida das brechas do velho discurso, e solidária daquele. Quer queiram quer não, esses velhos discursos injectam toda a sua força de estereótipos na palavra que os contradiz, dinamizam-na. A intertextualidade fá-los assim financiar a sua própria subversão (JENNY, 1979, p.44).

O narrador se coloca de maneira tal que, ao comentar as notícias dos jornais da época que eram censurados -subverte o sentido do discurso do qual se apropria, mostrando seu posicionamento de defender uma verdade que não era espelhada por esse discurso. É o caso da citação que se segue:

Agora que veio o tempo da Páscoa, o governo mandou distribuir por todo o país bodo geral, assim reunindo a lembrança católica dos padecimentos e triunfos de Nosso Senhor às satisfações temporárias do estômago protestativo. Os pobrezinhos fazem bicha nem sempre paciente às portas das juntas de freguesia e das misericórdias, e já se fala que para os finais de Maio se dará uma brilhante festa no campo do Jockey Club a favor dos sinistrados das inundações do Ribatejo, esses infelizes que andam de fundilhos molhados há tantos meses, formou-se a comissão patrocinadora com o que temos de melhor no high-life, senhoras e senhores que são ornamento da nossa melhor sociedade, podemos avaliar pelos nomes, qual deles o mais resplandecente em qualidades morais e bens de qualidade, Mayer Ulrich, Perestrello, Lavradio, Estarreja, Daun e Lorena, Infante da Câmara, Alto Mearim, Mousinho de Albuquerque, Roque de Pinho, Costa Macedo, Pina, Pombal, Seabra e Cunha, muita sorte vão ter os ribatejanos se conseguirem aguentar a fome até Maio.

No entanto, os governos, por supremos que sejam, como este, perfeitíssimo, sofrem de males da vista cansada, talvez da muita aplicação ao estudo, da pertinaz vigília e vigilância. É que, vivendo alto, só enxergam bem o que está longe, e não reparam como tantas vezes a salvação se encontra, por assim dizer, ao alcance da mão, ou no anúncio do periódico, que é o caso presente, e se este não viram menos desculpa têm, porque até traz desenho, uma senhora deitada, de combinação e alcinhas, entremostrando um magnífico busto que talvez deva alguma coisa às manipulações de Madame Hélène Duroy, não obstante está um pouco pálida a deliciosa criatura, um nadinha clorótica, ainda assim não tanto que venha a ser fatal esta sua doença, tenhamos confiança no médico que está sentado à cabeceira, careca, de bigode e pêra, e que lhe diz, respeitosamente repreensivo, Bem se vê que não $\mathrm{O}$ conhece, se $\mathrm{O}$ tivesse tomado não estava assim, e estende-lhe a insinuante salvação, um frasco de Bovril. Lesse o governo com atenção suficiente os jornais sobre os quais todas as manhãs, tardes e madrugadas mandou passar zelosos olhares, peneirando outros conselhos e opiniões, e veria quão fácil é resolver o problema da fome portuguesa, tanto a aguda como a crónica, a solução está aqui, no Bovril, um frasco de Bovril a cada português, para as famílias numerosas o garrafão de cinco litros, prato único, alimento universal, pancresto remédio, se o tivéssemos tomado a tempo e horas não estávamos na pele e no osso, Dona Clotilde.

Ricardo Reis vai-se informando, toma nota destas receitas úteis, não é como o governo, que insiste em fatigar os olhos nas entrelinhas e nas adversativas, perdendo o certo pelo duvidoso. (SARAMAGO, 1984, p.262 e 263)

O narrador, servindo-se de fragmentos do discurso da época, presente nos jornais, subverte o sentido do discurso original. Instalando sua máquina nas brechas do discurso, 
vemos a notícia original da distribuição de bodos aos pobres pela Páscoa, transformada pelo narrador na notícia da distribuição dos mesmos bodos aos mesmos pobres, reunida à lembrança católica dos padecimentos e triunfos de Cristo, sendo a Páscoa a festa católica que celebra a ressurreição. O narrador aproveita-se do discurso original, para dizer ao leitor que a Igreja estava aliada ao Estado para ajudar o governo a controlar ideologicamente os mais pobres, servindo ao Salazarismo.

Prosseguindo, o narrador retira do jornal a notícia de brilhante festa no Jockey Club em benefício das vítimas das inundações no Ribatejo, dando-nos os dados que nos informam que, enquanto "os infelizes andam de fundilhos molhados" há meses, a "solução" apresentada será uma festa com o "melhor da sociedade" portuguesa e que "sorte" será mesmo a dos pobres que agüentarem a fome até a realização da festa. Em seguida, servindo-se do discurso da propaganda da página do jornal, que anuncia um "milagroso" fortificante, o narrador ironiza o governo, "perfeitíssimo", que não percebeu que no fortificante milagroso estaria a solução para a fome portuguesa. Ao enunciar a propaganda enganosa, ilustrada pelo desenho de uma sensual mulher, com um "magnífico busto" e lingerie de alcinhas, instando o governo a enxergar ali uma solução para a fome, o narrador equipara os dois discursos: o do anúncio do auxílio aos famintos àquele que promete o milagre da saúde instantânea. O narrador ainda atribui a falta de visão do governo, que não enxergou o anúncio ilustrado talvez à "vista cansada" da "pertinaz vigília e vigilância" exercida por ele nos jornais, os mesmos "sobre os quais todas as manhãs, tardes e madrugadas mandou passar zelosos olhares", chamando a atenção do leitor para o exercício da censura, feita nos jornais da época.

Desta forma, o leitor pode observar como o uso, no texto saramaguiano, do discurso dos jornais de época, através da intertextualidade, "financia" a subversão de seu sentido original, propiciando a abertura de um novo sentido, captável a partir da decifração da ironia, instrumento privilegiado pelo autor português.

Terminamos com uma citação de Laurent Jenny que a nosso ver ilumina o uso da intertextualidade em toda a narrativa de $O$ ano da morte de Ricardo Reis: "A intertextualidade é pois máquina perturbadora. Trata-se de não deixar o sentido em sossego - de evitar o triunfo do "cliché" por um trabalho de transformação" (JENNY, 1979, p. 44).

\section{Referências}

BERRINI, Beatriz (org.). José Saramago - uma homenagem. São Paulo: FAPESP-EDUC, 1999. 
CAMÕES, Luís de. Os lusíadas. Rio de Janeiro: Biblioteca do Exército Editora, 1980.

JENNY, Laurent. A estratégia da forma. In: Intertextualidades. Tradução da revista Poétique número 27. Lisboa: Almedina, 1979, p.19-45.

KRISTEVA, Julia. Ensaios de literatura. Rio de Janeiro: Eldorado, 1974.

NITRINI, Sandra. Literatura comparada: história, teoria e crítica. São Paulo: EDUSP, 1997.

PESSOA, Fernando. Obra poética. Rio de Janeiro: Nova Aguilar, 1983.

SARAMAGO, José. O ano da morte de Ricardo Reis. Lisboa: Editorial Caminho, 1984.

VENTURA, Susanna Ramos. Escritores revisitam escritores (A leitura de Fernando Pessoa Ricardo Reis, por José Saramago e de Graciliano Ramos e Cláudio Manuel da Costa, por Silviano Santiago). 2001. 194 folhas. Dissertação de Mestrado. Universidade de São Paulo. 